\title{
The Effect of Family Planning Methods on Food Security in Oyo State, Nigeria
}

\author{
Adepoju Adebusola Adenike \\ Ladoke Akintola University of Technology, Ogbomoso, Nigeria
}

\begin{abstract}
This study affirms the effect of family planning on rural household food security. The major thrust of this research identified socio-economic characteristics of respondents, various family planning methods used, benefit of use and factors influencing household food security in the study area. The research was carried out in 4 Local Government areas (LGAs) of Oyo state, where five communities each were randomly selected from the LGAs. A total of 272 households were sampled from the 20 communities. Descriptive and multinomial logit regression were used to analyse data collected. Findings revealed that $64.4 \%$ of the respondents were female, mean age was 40 years; about $80 \%$ of them were married and most of them had formal education with average of 10years spent in school. Result further revealed that that most of the respondents adopt artificial method of family planning. Sex, marital status of respondent, number of children; primary occupation, traditional method, natural method and artificial method of family planning were the factors influencing household food security status. It was recommended that rural household should be enlightened on the advantages of the use of family planning to improve their household nutritional intake level as well as standard of living.
\end{abstract}

Key words: Food security, rural household, family planning, multinomial logit.

\section{Introduction/Problem Statement}

Food security is the provision of food to ensure its adequate supply for all people to live active and healthy lives [1]. It also entails production of food that will go round every citizen both in quantity and quality. That is, the availability or adequacy of food supplies in terms of quantity and variety of food. In essence, it implies secured and sustainable access to available supplies by all who need them for the maintenance of healthy and active life. Hence food insecurity can be referred to as the inability of a country to secure enough food and adequate dietary intake of all household members and at all times in order to live an active and healthy life [2].

Adefabi and Aderoju [3] identify two major types of food insecurity namely, transitory and chronic insecurity. Transitory food insecurity according to them is said to occur when a household's access to

Corresponding author: Adepoju Adebusola Adenike, Dr., Ph.D., research field: agricultural development and policy. sufficient food declines temporarily as a result of instability in food production, income as well as prices of food. Chronic insecurity, on the other hand is referred to as continuous inadequate diet by the population of a given country which arises as a result of lack of income or lack of resources.

Income and price influence the consumption of food not necessarily or directly the consumption of nutrients derived from food. When people spend more on food, they may or may not obtain better nutrition. Some of their additional expenditures go for a larger quantity of food but much of it especially, above minimal income levels go for higher quality [4]. Quality can be viewed subjectively by the consumer following his or her tastes. Food regarded as higher in quality need not be more nutritious than less favoured ones and they may even be nutritionally inferior. Every nutritionist can tell stories about the deterioration in nutritional standards as development proceeds: Carbonated beverages replace natural drinks, commercial infant foods replace mothers' breast milk 
and various junk foods are being increasingly consumed by children and adults. Statistics make it clear however that these cases run against the general pattern of improved nutrition in relation to increasing income. The household spend an increasing amount but a decreasing proportion of income on food as their income rises, very poor households devote more than half of their income on food and have relatively high income elasticity of demand for food.

In Nigeria, the percentage of food insecure house was reported to be 18 per cent in 1996 and over 40 per cent in 2005 [5]. Although, figures released by Food and Agricultural Organization in 2005 on the state of food insecurity in the world, indicated that 9 per cent of Nigeria's population was chronically undernourished between 2000 and 2002 (FAO, 2005). Food security is an age long concept as the quality of life of a people, and as such, a household needs to ascertain how to feed, and continue to feed its members [6]. However, food security is said to exist when all people at all times have physical and economic access to sufficient, safe and nutritious food to meet their dietary needs and food preferences for an active and healthy life [7]. Consequently, in Nigeria, food security which goes with food self-sufficiency and sustainability is still elusive [8]. This is because the agricultural sector has not been able to deal effectively with the problem of food security as related to increase in population which can be controlled by family planning.

Food security issues can be linked to two major theories: the Malthusian Population theory and Abraham Maslow's hierarchy of need theory of human motivation. According to Malthus as reported [9], there exist a great dichotomy in the rate of growth of population and food production. He argued that while population increased in geometric progression, food production increased in Arithmetic progression. He therefore contends that in due course, there would be acute shortage in food supply which will bring about fall in the standard of living. He later advocated for preventive checks such as "moral restraints" such as abstinence from marriage, family planning and limit the number of progeny, to reduce high population growth rate. His theory has not been proved wrong concerning this issue in Nigeria and other African countries which are having the challenges of food security in the present time and the quest to satisfy man's primary need of food consumption. Therefore, to meet this need agriculture must be given serious attention.

On the other hand, family planning is known to allow individuals and couples to anticipate and attain their desired number of children and the spacing and timing of their births. It is achieved through use of contraceptive methods and the treatment of voluntary infertility. A woman's ability to space and limit her pregnancies has a direct impact on her health and well-being as well as on the outcome of each pregnancy [10]. This consequently enhances the overall welfare of the household at large especially in the area of food security. Family planning services are defined as educational, comprehensive medical or social activities which enable individuals, including minors, to determine freely the number and spacing of their children and to select the means by which this may be achieved.

Typically large family size has significant relationship with much greater risk of poverty. Obamiro et al. [11] reported that an increase in household size would likely lead the household membership to food insecure group. In Nigeria, the production of food has not increased at the rate that can match the food demand of the increasing population. While food production increases annually at the rate less than 2.5 per cent, food demand increases annually at a rate more than 3.5 per cent due to the high rate of annual population growth of 2.83 per cent [12]. Recent study by Adebayo [13] shows that large family size has negative effect on food security, the results of this study indicated that about 60 per cent had family size of 5 and 8 members. Only 
24.5 per cent were food secure; hence, the need for family planning.

Raising a child requires significant amounts of resources: time, social, financial and environmental resources. Family planning can help assure that resources are available. The purpose of family planning is to make sure that any couple, man, or woman who has the desire to have a child has the resources that are needed in order to complete this goal. Through these resources a couple can explore the options of natural birth, surrogacy, artificial insemination or adoption. In the other case, if the person does not wish to have a child at the specific time, they can investigate the resources that are needed to prevent pregnancy, such as birth control, contraceptives, or physical protection and prevention.

Food insecurity is common in less developed countries and Nigeria is no exception. Audu-Bida [14] reiterated that about seven states of Nigeria were currently at the risk of food insecurity and nutrition crises. The persistence of hunger in many parts of the country being juxtapose with good surpluses and stocks in some other parts. The rising food prices results in wide spread of food insecurity, starvation and finally deaths due to wide spread poverty and poor implementation of government agricultural programmes.

As an illustration of food problems to come due to over population, Lester Brown [15] projected the world is likely to witness severe starvation and economic dislocation over the next 30 years. Nigeria in 2011 was the world's 7th most populated country with a population of 162 million people and In 2050, Nigeria would be the world's 3rd most populated country after India and China, outstripping the USA with an estimated population of between 230 and 430 million people. Nigeria is threatened by food insecurity presently and might face hunger, starvation and even death in the nearest future if the population is not controlled by family planning [16]. Household food security depends not only on the availability, affordability and sustainability supply of food but also on the coping strategies employed by households for its acquisition among which is spacing of child birth.

In Nigeria presently, several issues can be identified as the causes of food insecurity among these are firstly, the spread and impact of war and conflict disrupts food production, creates refugees and displaced person and keep land out of cultivation e.g. Boko haram invasion in the northern part of the country and intercommunity clashes. Secondly, with huge debt burden, the country needed a significant proportion of export earnings hence, the need for covers supply at the expense of home use coupled with increase Globalized Market. This in combination with increased urbanization has led to shift from food crops to cash crops production on the best land. Thirdly is underdeveloped agricultural sector mostly characterized by over reliance on primary agriculture, low soil fertility, minimal use of external farm inputs, environmental degradation, significant food crop loss (both to pre and post-harvest) etc. The impact of oil boom on the agricultural sector has equally affected the sector as the mainstay of Nigeria economy which invariably reduce the sectors contribution to food production and culminate to food insecurity.

In addition to these, is the existence of disease and infection such as Malaria, tuberculosis and HIV/AIDS not only reduce the man-hours available to agriculture and household food acquisition but also increase the burden of household in acquiring food as well as climate change with its attendant impact as loss of biodiversity in the ecosystem and other physical access. Lastly, it is worthy to note that farming activities are done mainly by the farmers who do not have access to necessary wherewithal for optimal production of food in Nigeria. The World Bank's (2013) statistics show that about 90 per cent of Nigeria's agricultural output comes from inefficient small farmers who have little or no access to fertilizers, irrigation or other modern inputs. Consequently, such farmers are only able or even struggle to produce enough food to sustain their immediate families. 
A number of lessons emerge from the current and projected future population dynamics of Nigeria with major implications for agriculture and food security. Therefore, there is need for the articulation of a green deal for Nigeria. In view of these, this study examined the effect of family planning on food security. Specifically, it profiled the respondents based on socio-economics characteristics, examined the expenditure pattern of the profiled respondents, identify the various method of family planning adopted in the study area, identify the perceived benefits of family planning on household food security and determine the factors influencing food security status of the farming household.

Hypothesis of the study:

$\mathrm{H}_{\mathrm{o} 1}$ : Selected socio-economic characteristics have no effect on the food security of the respondents.

$\mathrm{H}_{02}$ : There is no significant relationship between the use of family planning and the household food security status.

\section{Materials and Methods}

Study area. The study was carried out in Oyo state, Nigeria. Oyo state covers a total of 28,454 square kilometres of land mass. It is bounded in the south by Ogun state and in the north Kwara state, in the west by partly Republic of Benin while in the east by Osun state. By 2006 census, the population of Oyo state is $6,617,720$ people with the capital located at Ibadan [17]. Agriculture is the main occupation of the people in Oyo state. The climate is equatorial, notably with dry and wet seasons and high relative humidity. The dry season lasts from November to March while the wet season starts from April and ends in October. Average daily temperature ranges between $25{ }^{\circ} \mathrm{C}$ $\left(77.0^{\circ} \mathrm{F}\right)$ and $35^{\circ} \mathrm{C}\left(95.0^{\circ} \mathrm{F}\right)$ almost through the year. The climate in the state favours the cultivation of crops such as maize, yam, cassava, millet, rice, plantains, cocoa, palm produce, cashew etc. There are also cattle ranches at Saki, Fasola and Ibadan as well as dairy farm at Monatan in Ibadan. In addition, there are a number of government established farm settlements in some parts of the state.

Sampling procedure and sampled size: Multistage sampling technique was employed for the study. In the first stage, simple random sampling technique was used to select two Agricultural Development Programme (ADP) agricultural zones from the four ADP agricultural zones in Oyo state. Stratified sampling technique which forms the second stage was used to divide the Local Government Areas (LGAs) under the selected ADP agricultural zones into urban and rural as indicated by the Ministry of Local Government and chieftaincy offices of the state. The third stage involves the use of simple random sampling technique to select two rural LGAs from each of the two agricultural zones considered in the study. Five villages each were randomly selected from each of the selected LGAs at the fourth stage. Finally, using a proportionate to size sampling, 272 households were sampled in the study area.

Analytical technique: The primary data obtained were analysed using descriptive statistics and multinomial logit regression models. Household were categorized into food security levels using Food Expenditure Approach to food security measurement.

\subsection{Measurement Of Food Security}

Households' Food Expenditure Approach to food security measurement (Construction of Food Security Index). According to Omonona and Agoi [18] the households were classified into food secure, moderately food secure and food insecure households using households' food expenditure approach to construct food security index which was also adopted by Adepoju and Olawuyi [19]; this was used to establish the food security status of various households. It is given by:

$\mathrm{Fi}=\frac{\text { per capita food expenditure for the ith household }}{2 / 3 \text { Mean per capita food expenditure of all households }}$

Where $\mathrm{Fi}=$ food security index

When $\mathrm{Fi} \geq 1$ = food secured ith household and 
When Fi $\leq 1$ = food insecure ith household (further categorised into moderately food secured and food insecured household)

A food secured household is therefore those whose per capita monthly food expenditure fall above or is equal to two-third of the mean per capita food expenditure. While moderately food secured are households whose mean per capita food expenditure falls between two-third and one-third of the mean per capita food expenditure. On the other hand, a food insecure household is that household whose per capita food expenditure falls below one-third of the mean monthly per capita food expenditure.

\subsection{Multinimial Logit Model}

Following Fakayode et al. [20] multinomial logit regression model was used to express the probability of a household belonging to a particular food security category. The households were categorized into three based on their monthly expenditure on food. The food security categories include; food secured, moderately food secured and food insecure households. The general form of the multinomial Logit model is:

$$
\operatorname{Pr}\left(y_{i}=j\right)=\frac{\exp \left(X_{i} \beta_{j}\right)}{1+\sum_{j=1}^{j} \exp \left(X_{i} \beta_{j}\right)}
$$

In order to ensure identifiability,

$$
\operatorname{Pr}\left(y_{i}=0\right)=\frac{1}{1+\sum_{j=1}^{j} \exp \left(X_{i} \beta_{j}\right)}
$$

where for the ith individual, $y_{i}$ is the observed outcome and $X_{i}$ is a vector of explanatory variables. $\beta_{j}$ is the unknown parameters. For this study, the model was summarized as follows:

$$
P_{i j}=\frac{\exp \left(x_{i} \beta_{j}\right)}{1+\sum_{j=1}^{3} \exp \left(x_{i} \beta_{j}\right)} \text { for } j=1,2,3
$$

$P_{i j}$ is the probability of being in each of the groups 1and 2 .

$$
\begin{gathered}
P_{i 0}=\frac{1}{1+\sum_{j=1}^{3} \exp \left(X_{i} \beta_{j}\right)} \text { for } j=0 \\
\ln =\frac{P_{i j}}{P_{i 0}} X_{i} \beta_{j}
\end{gathered}
$$

$P_{i 0}$ is the probability of being in the reference group or group 0 . In practice, when estimating the model, the coefficients of the reference group are normalized to zero [21, 22]. This is because, the probabilities for all the choices must sum up to unity [22]. Hence, for three choices (3-1), only distinct sets of parameters can be identified and estimated. The natural logarithms of the odd ratio of equations (1) and (2) give the estimating equation as:

$$
\beta_{3}=-\left(\beta_{1}+\beta_{2}\right)
$$

This denotes the relative probability of each of the group 1 and 2 (moderately food secured and food insecure) to the probability of the reference group (food secured). The estimated coefficients for each choice therefore reflect the effects of $X_{i}$ 's on the likelihood of the respondents falling into the alternative relative to the reference group. The coefficients of the reference group however, may be recovered by using the formula

$$
\left.P_{i j}=\beta_{0}+\beta_{1} X_{1}\right)+\beta_{2} X_{2}+\ldots \ldots .+\beta_{15} X_{15}
$$

For each explanatory variable, the negative of the sum of its parameters for categories 1 and 2 is the parameter for the reference group. The partial derivatives otherwise called the marginal effects (" $P_{j} /$ " $X_{i}$ ) is obtained by differentiating equations (3) and (4) with respect to the particular explanatory variable. The derivation techniques implicitly indicate that neither the sign nor the magnitude of the marginal effects need to bear any relationship to the sign of the coefficients used in obtaining them [22].

$P_{i j}=$ Food security status $(0=$ food secured, $1=$ moderately food secured, 2 = food insecure).

$\mathrm{X}_{1}=\operatorname{Sex}($ male $=1$, female $=0)$

$\mathrm{X}_{2}=$ Age (years)

$\mathrm{X}_{3}=$ Marital status $($ married $=1$, otherwise $=0)$

$\mathrm{X}_{4}=$ Number of children (number)

$\mathrm{X}_{5}=$ No of dependants (actual number)

$\mathrm{X}_{6}=$ Number of working adults

$\mathrm{X}_{7}=$ Level of education (years)

$\mathrm{X}_{8}=$ Farming status (full-time $=1$, part-time $=0$ )

$\mathrm{X}_{9}=$ Membership in association (member $=1$, otherwise $=0$ ) 
$\mathrm{X}_{10}=$ Farm enterprise $($ crop production $=1$, otherwise $=0$ )

$\mathrm{X}_{11}=$ Traditional method (yes $=1$, otherwise $=0$ )

$\mathrm{X}_{12}=$ Natural method (yes $=1$, otherwise $=0$ )

$\mathrm{X}_{13}=$ Modern method $(\mathrm{yes}=1$, otherwise $=0$ )

\section{Results and Discussion}

\subsection{Socio-economic Characteristics of the Respondents}

The socio economic characteristics of the respondents identified in this study are presented in Table 1. The profiled distribution of respondents according to the level of food security as indicated by the total figures reveals that $58.1 \%$ of the sampled household are food secured, $28.3 \%$ and $13.6 \%$ are moderately food secured and food in-secured respectively. This implies that majority of the respondents in the study area are food secured.

The distribution of the profiled respondents according to their age reveals that, about $39.71 \%$ of the respondents fall within the age range of 31-40 years and this accounted for the highest value. About $48 \%$ of these age category are food secured. The least value however is $4.78 \%$ which accounts for those above 60 years. The mean age of the respondents is 40.33 years. This is an indication that, most of the respondents are in their productive and active age so their need for family planning to ensure household well-being. Majority of the respondents are female $65.44 \%$ while $34.56 \%$ of the respondents accounted for male respondents. The female counterpart has the higher percentage of representation due to the fact that most of the family planning methods are usually used by them.

It is also worthy to note that, the distribution of the respondents based on their marital status shows that $58.1 \%$ of the respondents are married. It is noteworthy to mention that none of the respondents has never being married at one point in time or the other even though $13.6 \%$ of the respondents were divorced at the time the research was carried out. Also, none of the separated or divorced respondents falls under the food insecured category. About half of the respondents (54.0\%) have between 7-9 household members while only $10 \%$ of them have above 12 household members. Forty-five percent each of respondents that are food secured and moderately food secured have between 4-6 members in their household. The mean household size in the study area is 8 members which signify that many of the rural households have fairly large family. The reason for this is not far-fetched as many need family labour to help on the farm to reduce their cost of production.

In addition, the educational level result indicates that $33.8 \%$ of the respondents spent between 13 and 18 years in school which implies that they have a post-secondary education. This is closely followed by respondents with primary education (31.6\%). However, the least value $1.1 \%$ accounted for those who are post graduates and they fall under the food secured household category. The mean of the years spent in school is 10 years which is higher than the basic 9 years of educational policy adopted in Nigeria. The implication of this is that education level results in awareness and/or adoption of potential family planning suitable for individual to enhance the household welfare. An average household (51.5\%) in the study area have no less than two working adults in the household, while only $5.5 \%$ of them claim to have four adult working members within their household. The mean of working adults is two, an indication that an average respondents has the maximum of two working adults in the household which influence the availability of resources which in turn enhance household food security. Results further reveals that $57.3 \%$ of the respondents have less than 10 years of farming experience and this accounted for the highest value while the least value $3.0 \%$ accounted for those who have above 25 years of farming experience. The mean year of experience is 13.1 years. This is an indication that majority of the farmers have been into farming for a long time, an activity that ensures food security of the household. 
Table 1 Socio-economic characteristics of the respondents.

\begin{tabular}{|c|c|c|c|c|c|}
\hline $\begin{array}{l}\text { Socio economic } \\
\text { characteristics }\end{array}$ & $\begin{array}{l}\text { Food secured freq } \\
(\%)\end{array}$ & $\begin{array}{l}\text { Moderately food } \\
\text { secured freq }(\%)\end{array}$ & $\begin{array}{l}\text { food insecure freq } \\
(\%)\end{array}$ & $\begin{array}{l}\text { Total } \\
\text { freq }(\%)\end{array}$ & Mean (std. deviation) \\
\hline \multicolumn{6}{|l|}{ Age(yrs) } \\
\hline$<30$ & $19(34.5)$ & $26(47.3)$ & $10(18.2$ & $55(20.2)$ & \multirow[t]{13}{*}{$40.3(9.9)$} \\
\hline $31-40$ & $52(48.2)$ & $40(37.0)$ & $16(14.8)$ & $108(39.7)$ & \\
\hline $41-50$ & $61(82.4)$ & $8(10.8)$ & $5(6.8)$ & $74(27.2)$ & \\
\hline $51-60$ & $20(90.9)$ & $1(4.5)$ & $1(4.5)$ & $22(8.1)$ & \\
\hline Above 60 & $6(46.1)$ & $2(15.4)$ & $5(38.5)$ & $13(4.8)$ & \\
\hline \multicolumn{5}{|l|}{$\operatorname{Sex}$} & \\
\hline Male & $54(57.5)$ & $30(31.9)$ & $10(10.6)$ & $94(34.6)$ & \\
\hline Female & $104(58.4)$ & $47(26.4)$ & $27(15.7)$ & $178(65.4)$ & \\
\hline \multicolumn{5}{|l|}{ Marital status } & \\
\hline Single & $0(0.0)$ & $0(0.0)$ & $0(0.0)$ & $0(0.0)$ & \\
\hline Married & $138(87.3)$ & $11(7.0)$ & $9(5.7)$ & $158(58.1)$ & \\
\hline Separated & $72(93.5)$ & $5(6.5)$ & $0(0.0)$ & $77(28.3)$ & \\
\hline Divorced & $35(94.6)$ & $2(5.4)$ & $0(0.0)$ & $37(13.6)$ & \\
\hline \multicolumn{6}{|l|}{ Household size } \\
\hline$<3$ & $0(0.0)$ & $0(0.0)$ & $0(0.0)$ & $0(0.0)$ & \multirow[t]{5}{*}{$8.2(2.1)$} \\
\hline $4-6$ & $27(45.0)$ & $27(45.0)$ & $6(10.0)$ & $60(22.1)$ & \\
\hline $7-9$ & $85(57.8)$ & $45(16.5)$ & $17(4.7)$ & $147(54.0)$ & \\
\hline $10-12$ & $41(74.5)$ & $3(5.5)$ & $11(20.0)$ & $55(20.2)$ & \\
\hline Above 12 & $5(50.0)$ & $2(20.0)$ & $3(30.0)$ & $10(3.7)$ & \\
\hline \multicolumn{6}{|l|}{ Education } \\
\hline 0 & $14(82.4)$ & $2(11.7)$ & $1(5.9)$ & $17(6.3)$ & \multirow[t]{5}{*}{$10.3(5.5)$} \\
\hline $1-6$ & $43(50.0)$ & $24(27.9)$ & $19(22.1)$ & $86(31.6)$ & \\
\hline $7-12$ & $65(87.8)$ & $2(2.7)$ & $7(9.5)$ & $74(27.2)$ & \\
\hline $13-18$ & $33(35.8)$ & $49(53.3)$ & $10(10.9)$ & $92(33.8)$ & \\
\hline Above 18 & $3(100.0)$ & $0(0.0)$ & $0(0.0)$ & $3(1.1)$ & \\
\hline \multicolumn{6}{|l|}{ Working adult } \\
\hline 1 & $40(61.50)$ & $20(30.8)$ & $5(7.7)$ & $65(23.90$ & \multirow[t]{4}{*}{$2.1(0.8)$} \\
\hline 2 & $81(5.8)$ & $46(32.9)$ & $13(9.3)$ & $140(51.5)$ & \\
\hline 3 & $28(53.8)$ & $10(19.2)$ & $14(27.0)$ & $52(19.1)$ & \\
\hline 4 & $9(64.3)$ & $1(7.1)$ & $4(28.6)$ & $14(5.5)$ & \\
\hline \multicolumn{6}{|l|}{ Pry Occupation } \\
\hline Civil service & $58(62.4)$ & $20(21.5)$ & $15(16.1)$ & $93(34.5)$ & \\
\hline Artisans & $37(62.7)$ & $13(22.0)$ & $9(15.3)$ & $59(21.7)$ & \\
\hline Farming & $49(49.5)$ & $42(42.4)$ & $8(8.1)$ & $99(36.4)$ & \\
\hline Trading & $11(91.7)$ & $1(8.3)$ & $0(0.0)$ & $12(4.4)$ & \\
\hline Transport service & $3(33.3)$ & $1(11.1)$ & $5(55.6)$ & $9(3.3)$ & \\
\hline \multicolumn{6}{|c|}{$\begin{array}{l}\text { Farming experience } \\
\text { (yrs) }\end{array}$} \\
\hline$<5$ & $15(100.0)$ & $0(0.0)$ & $0(0.0)$ & $15(5.5)$ & \multirow[t]{6}{*}{$13.1(11.5)$} \\
\hline $6-10$ & 69 (48.9) & $56(39.7)$ & $16(11.3)$ & $141(51.8)$ & \\
\hline $11-15$ & $42(68.9)$ & $14(22.9)$ & $5(8.2)$ & $61(22.4)$ & \\
\hline $16-20$ & $25(61.0)$ & $5(12.2)$ & $11(26.8)$ & $41(15.1)$ & \\
\hline $20-25$ & $5(83.3)$ & $1(16.7)$ & $0(0.0)$ & $6(2.2)$ & \\
\hline Above 25 & $2(25.0)$ & $1(12.5)$ & $5(62.5)$ & $8(3.0)$ & \\
\hline Total & $158(58.1)$ & $77(28.3)$ & $37(13.6)$ & $272(100.0)$ & \\
\hline
\end{tabular}

Note: Figures in parentheses are the percentages.

Source: Fieldwork summary data analysis 2014. 


\subsection{Household Distribution of Monthly Expenditure}

The average distribution of the monthly expenditure for the households in the study area is presented in Table 2. The highest proportion of the monthly expenditure by household is on food and this accounted for $49.9 \%$ of the total expenditure. This is followed by expenses on education expenses of the respondents' children which has also accounted for $14 \%$. The proportion of expenses spent on housing is minimal relative to other basic needs of life $(4 \%)$ of total monthly expenditure is spent on rent allowance. This may be due to the fact that majority of the respondents claim non-payment for housing because they live within their family house while others who reside in their personal houses did not indicate how much it could cost them if it was not their house. The least cost for an average household in the study area is water $(1 \%)$. Many of the respondents claimed that they source their water from nearby streams or wells that were close to their homes. In all, an average total of $¥ 43,975.52$ was spent monthly by each household, which is about $\$ 1,500 /$ household/day irrespective of the household size.

\subsection{Household Monthly Expenditure Pattern by Categories}

The household expenditure was used as a proxy for household income, because most respondents rarely disclose their actual income, as an individual is not expected to spend more than they earn. Based on the three categories of household food security, it worthy to note that only the food secured household spent less on food expenditure ( $\$ 30,382.39)$ relative to non-food expenditure $(\$ 33,477.72)$ when compared to their other counterparts. The mean household food expenditure for moderately and food insecurity are $\$ 11,228.71$ and $\$ 8,118.78$ respectively. About $73 \%$, $37 \%$ and $41 \%$ of total household expenditure accounted for the expenses made on non-food for food secured, moderately food secured and food insecure household respectively.

\subsection{Identified Methods of Family Planning}

The distribution of the respondents according to methods of family planning adopted is presented in Table 4. About $63 \%$ of the respondents indicated that they use traditional method of family planning to prevent unwanted pregnancy. Four different types of traditional method were identified during the cause of the study and these include the use of incisions, herbal, vinegar and charms. About 33\% of the respondents used herbal method while $8.5 \%$ used vinegar and charms.

Furthermore, $63.2 \%$ of the respondents claim to use natural method of spacing children. Some of the

Table 2 Distribution of household monthly expenditure.

\begin{tabular}{lll}
\hline Monthly expenditure & Average value (N) & Percentage \\
\hline Food & $21,931.69$ & 49.9 \\
Toiletries & 955.11 & 2.2 \\
Clothing/ foot wear & $2,854.98$ & 6.5 \\
Rent allowance & $1,777.90$ & 4.0 \\
Water & 477.10 & 1.1 \\
Electricity & $1,204.78$ & 2.7 \\
Health & $1,102.39$ & 2.5 \\
Education & $6,191.73$ & 14.1 \\
GSM maintenance & $1,643.93$ & 3.7 \\
Firewood /Gas/ Kerosene & $1,712.21$ & 3.9 \\
Generator fuel & $1,531.03$ & 3.5 \\
Transport & $1,441.51$ & 3.3 \\
Remittances & $1,161.65$ & 2.6 \\
Total & $43,975.52$ & 100.0 \\
Mean per capita expenditure & $5,483.61$ & \\
\hline
\end{tabular}

Source: Fieldwork summary data analysis 2014. 
Table 3 Distribution of Household based on monthly expenditure pattern by categories.

\begin{tabular}{lllll}
\hline $\begin{array}{l}\text { Household Monthly } \\
\text { Expenditure }\end{array}$ & Food secured freq $(\%)$ & $\begin{array}{l}\text { Moderately food secured } \\
\text { freq }(\%)\end{array}$ & food insecure freq $(\%)$ & $\begin{array}{l}\text { Total } \\
\text { freq }(\%)\end{array}$ \\
\hline $\begin{array}{l}\text { Food } \\
<15,000\end{array}$ & $7(6.4)$ & $67(60.9)$ & $36(32.7)$ & $100(40.4)$ \\
$15,001-30,000$ & $76(87.3)$ & $10(11.5)$ & $1(1.2)$ & $87(32.0)$ \\
$30,001-45,000$ & $59(100.0)$ & $0(0.00)$ & $0(0.00)$ & $59(21.7)$ \\
$45,001-60,000$ & $16(100.0)$ & $0(0.00)$ & $0(0.00)$ & $16(5.9)$ \\
Mean N (\%) & $30,382.39(47.6)$ & $11,228.71(63.3)$ & $8,118.78(59.5)$ & $49,729.88(52.2)$ \\
& & & & $117(43.0)$ \\
Non-food & $5(4.3)$ & $75(64.1)$ & $37(31.6)$ & $69(25.4)$ \\
$<15,000$ & $67(97.1)$ & $2(2.9)$ & $0(0.00)$ & $59(21.7)$ \\
$15,001-30,000$ & $58(98.3)$ & $1(1.7)$ & $0(0.00)$ & $27(9.9)$ \\
$30,001-45,000$ & $27(100.0)$ & $0(0.00)$ & $0(0.00)$ & $45,521.96(47.8)$ \\
$45,001-60,000$ & $33,477.72(73.5)$ & $6,520.13(36.7)$ & $5,524.11(40.5)$ & $95,251.84(100.0)$ \\
Mean (N) & $63,860.11(100.0)$ & $17,748.84(100.0)$ & $13,642.89(100.0)$ & \\
Household total & & & & \\
expenditure N (\%) & & & & \\
\hline
\end{tabular}

Source: Fieldwork summary data analysis 2014.

Table 4 Methods of family planning adopted by categories.

\begin{tabular}{lllll}
\hline Family planning method & Food secured freq (\%) & $\begin{array}{l}\text { Moderately food } \\
\text { secured freq (\%) }\end{array}$ & food insecure freq (\%) & $\begin{array}{l}\text { Total * } \\
\text { freq }(\%) \\
171(62.9)\end{array}$ \\
Traditional methods & $69(40.4)$ & $71(41.5)$ & $31(18.1)$ & $40(14.7)$ \\
Incisions & $11(27.5)$ & $21(52.5)$ & $8(20.0)$ & $90(33.1)$ \\
herbal & $45(5.0)$ & $30(33.3)$ & $15(16.7)$ & $23(8.5)$ \\
Vinegar & $9(39.1)$ & $9(39.1)$ & $5(21.8)$ & $23(8.5)$ \\
Charms & $11(47.8)$ & $11(47.8)$ & $1(4.4)$ & $172(63.2)$ \\
Natural methods & $91(52.9)$ & $61(35.5)$ & $20(11.6)$ & $30(11.0)$ \\
& $25(83.4)$ & $4(13.3)$ & $1(3.3)$ & $73(26.8)$ \\
Abstinence & $13(17.8)$ & $40(54.8)$ & $20(27.4)$ & $81(29.8)$ \\
Prolong lactation & $35(43.2)$ & $32(39.5)$ & $14(17.3)$ & $11(4.0)$ \\
Absent menstruation & $3(27.3)$ & $5(45.4)$ & $3(27.3)$ & $14(5.8)$ \\
Celibacy & $5(38.5)$ & $7(53.8)$ & $1(7.7)$ & $10(3.7)$ \\
Exercise & $12(85.8)$ & $1(7.1)$ & $1(7.1)$ & $43(15.8)$ \\
Polygamy & $9(90)$ & $0(0.0)$ & $1(10.0)$ & $223(82.0)$ \\
Douching & $30(69.8)$ & $12(27.9)$ & $1(2.3)$ & $64(23.5)$ \\
Withdrawal & $139(62.3)$ & $54(24.2)$ & $30(13.5)$ & $51(18.6)$ \\
& $54(84.4)$ & $10(15.6)$ & $0(0.0)$ & $65(23.9)$ \\
Modern methods & $42(82.4)$ & $7(13.7)$ & $2(3.9)$ & $11(4.0)$ \\
Pills Injections & $55(84.6)$ & $5(7.7)$ & $5(7.7)$ & $10(3.7)$ \\
Male condoms & $11(100.0)$ & $0(0.0)$ & $0(0.0)$ & $29(10.7)$ \\
IUCD & $2(20.0)$ & $8(80)$ & $0(0.0)$ & $13(44.8)$ \\
Vasectomy & $4(13.8)$ & $12(41.4)$ & & \\
Contraceptive patch & & & & \\
\hline
\end{tabular}

*Multiple choices.

Source: Fieldwork summary data analysis 2014.

acclaimed methods utilized in the study area are abstinence from sexual intercourse, prolonged lactations for nursing mothers, celibacy, withdrawer methods among others. Absent menstruation accounted for $29.8 \%$ which is the highest closely followed by prolong lactation (26.8\%). However, these methods can only be used by nursing mothers. On the contrary, celibacy method which accounted for the least value is embraced by $4.0 \%$ of the respondents.

In addition, the distribution of the respondents 
according to the natural methods of family planning reveals that, majority i.e. $81 \%$ of the respondents claimed to use menstrual period as the basis for encouraging family planning. $11.03 \%$ abstain from sex, 26.84\% prevent unwanted pregnancy through injection of prolactin, $29.78 \%$ prevent unwanted pregnancy through celibacy, $4.78 \%$ encourage family planning through exercise, $5.15 \%$ indulge in polygamous act as a means of prevent unwanted pregnancy while $15.81 \%$ practiced withdrawal methods. However, the least value i.e. $3.68 \%$ of the respondents uses douching method for family planning. Among the food secured category, about $86 \%$ of them uses polygamy method as a way of spacing children i.e. by marrying more than one spouse while only $3.3 \%$ of the food insecure adopted the abstinence method as a way of child spacing.

It should however be noted that majority $(82.0 \%)$ of the sampled housed embraced the use of the modern methods of family planning. Some of the identified methods include the use of pills, injectable contraceptives, male and female condoms, intrauterus contraceptive device (IUCD), vasectomy and contraceptive patch. About $24 \%$ and $23.5 \%$ of the respondents claimed to use male condoms while the least method used by them is the use of vasectomy method (surgical procedures used to remove part or all of the vas deferens) to prevent unwanted pregnancy. None of the food insecure uses IUCD and vasectomy as a means of preventing unwanted pregnancy.

\subsection{Identification of the Reasons for Family Planning}

The distribution of the respondents according to reasons for utilization of family planning is presented in Table 5. The result reveals that majority of the respondents claimed they adopt family planning as a strategy to enhance mothers' health stability i.e. $81.99 \%$ and this accounted for the highest value. Next to this are respondents who claim to space their children so that they will have enough resources for their wards upbringing, this has a representation of $80.5 \%$. Some of the respondents adduce engaging in family planning create for them the ability to educate children within the household (68.4\%) and close to this is having the enablement to improve the standard of living of the household in terms of their general well-being (69.1\%). The least reason given for participating in family planning as affirmed by the respondents is to prevent sexually transmitted diseases.

\subsection{Factors Influencing Household Food Security}

The factors influencing household food security level are presented in Table 7. The table reveals that sex significantly affect food security status at $10 \%$. A male respondent who adopt family planning has the probability of being moderately food secured compared to their female counterpart. However, the female respondents are better off than the male counterpart in the food insecurity category. Age is also significant at $1 \%$ but have a negative relationship with food security status. This implies that a year increase in age of the respondents will reduce the probability of being secured by 0.0011 . On the other hand it was not significant for the probability of moving from food insecure to moderately food secured household.

Table 5 Households' reasons for engaging in family planning.

\begin{tabular}{lll}
\hline Variables & Frequency & Percentage \\
\hline Reasons & & \\
Provision of quality education for wards186 & & 68.4 \\
For mothers health stability & 223 & 81.9 \\
To stop malnutrition and poverty & 196 & 72.1 \\
Have resources for child upbringing & 219 & 80.5 \\
To improve household living standard & 188 & 69.1 \\
To prevent sexually transmitted diseases & 75 & 27.6 \\
\hline
\end{tabular}

Source: Fieldwork summary data analysis 2014. 
Table 7 Multinomial logit regression result.

\begin{tabular}{llllllll}
\hline Variables & coefficient & Std Error & $P$-value & coefficient & Std Error & $P$-value & dy/dx \\
\hline 0 (base outcome) & & & & & & & \\
1 & & & & & & \\
Sex & $2.3101^{*}$ & 1.3430 & 1.72 & $-4.0718^{*}$ & 2.1028 & -1.94 & -0.0215 \\
Age & $-0.2036^{* * *}$ & 0.0850 & -2.40 & 0.0013 & 0.1150 & 0.01 & 0.0011 \\
Marital status & $9.3120^{* * *}$ & 3.0670 & 3.03 & $12.8388^{* *}$ & 4.0400 & 3.18 & 0.0134 \\
No. of children & $-0.9509^{*}$ & 0.5027 & -1.89 & $-4.1531^{* * *}$ & 1.1854 & -3.50 & -0.0051 \\
No. of dependents & -0.4199 & 0.6625 & -0.63 & 0.2366 & 1.1891 & 0.20 & 0.0022 \\
No. of working adults & 0.7592 & 0.8099 & 0.94 & 2.1455 & 1.3086 & 1.64 & -0.0040 \\
Education (years) & 0.1577 & 0.1208 & 1.31 & 0.1173 & 0,1580 & 0.74 & -0.0008 \\
Pry occupation & -0.7207 & 1.3029 & -0.55 & $3.9249 *$ & 2.2576 & 1.74 & 0.0045 \\
Farming experience & 0.0313 & 0.0687 & 0.46 & $-0.2087 * *$ & 0.0989 & -2.11 & -0.0002 \\
Association Member & -0.370 & 1.1752 & -0.31 & 1.6275 & 1.5633 & 1.04 & 0.0019 \\
Farm enterprise & $-1.3674^{*}$ & 0.7239 & -1.89 & $-1.9019 *$ & 1.0548 & 1.80 & 0.0073 \\
Traditional method & 1.3163 & 1.5991 & 0.82 & $10.9843^{* * *}$ & 3.6991 & 2.97 & -0.0064 \\
Natural method & -3.3485 & 1.3281 & -0.26 & $-7.1515^{* * *}$ & 2.7514 & -2.60 & 0.0020 \\
Modern method & $-3.8501^{* *}$ & 1.8624 & -2.07 & 1.6289 & 2.9999 & 0.54 & 0.1106 \\
Food expenditure & $-0.0008^{* * *}$ & 0.0002 & -3.66 & $-0.0033^{* * *}$ & 0.0008 & -4.42 & $4.27 \mathrm{e}-06$ \\
Constant & $11.5061^{*}$ & 6.0121 & 1.91 & -0.2763 & 10.0717 & -0.03 & \\
\hline No & & &
\end{tabular}

No of observations $=272 ; \quad * * *$ significant at $1 \%$ level of significance

LR chi2 $(30)=427.14 ; \quad \quad * *$ significant at $5 \%$ level of significance

Prob $>$ chi $2=0000$; Pseudo $=0.8382 *$ significant at $10 \%$ level of significance

Log likelihood $=41.2339$

Source: Fieldwork summary data analysis 2014.

Marital status is significant at $1 \%$ and positively related to household food security level. This implies that being married will increase the possibility of improving food security status by 0.013 . Household food security level is also negatively related to the number of children in rural household. This is an indication that decrease in the number of children by 0.0051 will enhance household food security status from food insecurity status to moderately food secure and moderately food secure to food secure status. The result further ascertains that farming status of a household significantly affect the level of food security of the respondents. An increase in the number of farmers among the respondents will positively improve the food security status of the food insecure category by 0.0045 . However, this may not have effect on the moderately food secured category.

Contrary to apriori expectation, farm experience has a significant but negative effect on household food security status of the food insecure category. This implies that an increase in years of farming experience will reduce the food security status of the food insecure by 0.0002. Type of farming enterprise households engage in significantly determine the level of food security of respondents among the moderately food secured category. Furthermore, results reveals that other than crop production activities, engaging in other farm enterprise will enhance the food security level of the moderately food secured households by 0.0073 .

Household monthly expenditures on food significantly influence food security status of the household and negatively too. This indicates that an increase in household expenditure on food by the moderately food secured and food insecure households deteriorates their food security status (conflicting apriori expectation) by 0.00004 . An explanation to this can be deduced from the expenditure pattern of the three household food security categories where nonfood expenditure is far less than expenses on food consumption monthly. The result reveals the level of impoverishment of the two categories as most of their income earnings are expended on food to keep the family alive. 
Artificial family planning method significantly affect food security level for the moderately food secured category but negatively an indication that the use of other methods of family planning other than the artificial method will enhance their food security status. Also, in the food insecure category, both the traditional and natural methods of family planning positively and negatively influences food security status respectively. This is an indication that the use of other methods apart from the natural method will enhance household food security status and on a contrary for traditional method, increase in the use of this method will further enhance household food security status.

The foregoing therefore permits the rejection of the hypotheses that socio economic characteristics and use of family planning do not influence the household food security status of rural households in the study area.

\section{Conclusions}

The results of the findings revealed incidences of level of impoverishments of the rural households with regard to food security. It was discovered that rural household will be food secured or there will be food sufficiency if they engage more in family planning and increase farming activities. In conclusion, the contribution of family planning goes beyond gap filling, paying due attention to family planning has a significant role in addressing household food security in the future. The study therefore recommends that rural households should be more enlightened of the merits of child spacingto reduce food shortage in other to improve their nutritional intake level as well as standard of living.

\section{References}

[1] Anderson, M. 2009. "A Question of Governance: To Protect Agribusiness: Profits or the Right to Food?" Agribusiness Action Initiatives. http://www.iatp.org/files/258_2_107086.pdf.

[2] Oriola, E. O. 2009. "A Framework for Food Security and Poverty Reduction in Nigeria." European Journal of
Social Sciences 8 (1): 132-9.

[3] Adefabi, R. A., and Aderoju, B. R. 2011. Economics of Development. Ibadan: Isegun publishing company.

[4] Obodomu, J. O. 2006. "Information Technology and Food Security in Nigeria." Benue State University Journal of Education 7: 45-56.

[5] Sanusi, R. A, Badejo, C. A, and Yusuf, B. O. 2006. "Measuring Household Food Insecurity in Selected Local Government Areas of Lagos and Ibadan, Niger." Pakistan J. Nutr. 5 (1): 62-7.

[6] Food and Agricultural Organization 2004. Undernourishment around the world. FAO, Rome.

[7] Nyam, T. T. 2005. The concept and philosophy of the special programme for food security. Paper presented at the site level sensitization Workshop on concept and philosophy of the special programme for food security held at Makurdi, Otukpo and Kastina Alasties.

[8] Nworgu, F. C. 2005. "Prospects and Pitfall of Agricultural Production in Nigeria Ibadan." Blessed Publication Consultants/Publication.

[9] Olimar, O. O. 2011. Food Security and Population Growth in the 21 st Century.

[10] WHO 2011. WHO's Family planning cornerstones: safe and effective provision and use of family planning methods. Pp 9-102.

[11] Obamiro, E. O., Doppler, W., and Kormawa, P. M. 2003. "Pillars of Food Security in Rural Areas of Nigeria." Food Afr. Internet Forum 3-4: 7-10. Available at http://foodafrica.nri.org/security/securitypapers.html Accessed on 26 November 2012.

[12] Oluyole, K. A., and Lawal, J. O. 2008. "An Appraisal of the Impact of Agro-Services Corporation on Productivity." Proceedings of the 9th International Conference Precision Agriculture, 20-23, July, 2008.

[13] Adebayo, O. O. 2012. "Effects of Family Size on Household Food Security in Osun State, Nigeria." Asian Journal of Agriculture and Rural Development 2 (2): 136-41.

[14] Audu-Bida, S. 2010. "Potential Food Security and Nutrition Crisis in the Sahel Region of Nigeria." Paper Presented at the One-day Consultative Meeting Organized by the National Emergency Management Agency (NEMA).

[15] Lester Brown 2012. Full planet, Empty plates. The New Geopolitics of Food Scarcity Earth Policy Institutehttp://www.earth-policy.org/images/uploads/boo k_images/FullPlanetAllChaps.pdf.

[16] Chinedu, N. 2001. Nigeria's Agriculture and Food Security Challenges. Federal Ministry of Health. Mission Reporton field visits to Sokoto, Kano, Borno and Gombe States. Abuja: Federal Republic of Nigeria/FEWS NET.

[17] NPC, 2006. National Population Commission: state 
population

www.population.gov.ng/component/content/article/89.

[18] Omonoma, B. T., and Agoi, G. A. 2007. "An Analysis of Food Security Situation among Nigerian Urban Households: Evidence from Lagos State, Nigeria." Journal of Central European Agriculture 8 (3): 397-406.

[19] Adepoju, A. A., and Olawuyi, S. O. 2012. "Effect of Livelihood Activities on Food Security among Farmers in Oyo East Local Government Area of Oyo State, Nigeria." AAB Bioflux 4 (3): 112-21.

[20] Fakayode, A., Rahji, M. A. Y., Oni, O. A., and Adeyemi, S. 2009. "An Assessment of Food Security Situations of
Farm Households Ii Nigeria: AUSDA Approach." The Social Sciences 4 (1): 24-9. Medwell Jounals 2009.

[21] Kimhi, A. 1994. "Participation of Farm Owners in Farm and Off-farm Work including the Option of Full-time Off-farm Work." Journal of Agricultural Economics 45 (2): 232-9.

[22] Greene, W. H. 1993. Econometric Analysis. London: Macmillan.

[23] F.A.O, Report 2005. "Food and Agricultural Organization, the state of Food Insecurity in the World." Rome.

[24] http://www.e-ir.info/2011/07/18/food-security-and-popul ation-growth-in-the-21st-century/. 